\title{
ORIGINAL ARTICLE

CORE STABILIZATION EXERCISES AFTER ACL RECONSTRUCTION
SURGERY PROVIDES BETTER OUTCOMES: A RANDOMIZED
CONTROLLED TRIAL

\author{
${ }^{* 1}$ Dilpreet Kaur \\ ${ }^{2}$ Dr. Ravi Gupta \\ ${ }^{3}$ Dr. Shikha
}

\section{ABSTRACT}

Background: Decreased core stability displaces center of gravity away from base of support reducing activity participation of athlete. Present study was conducted to study the effect of core stabilization exercises after reconstruction surgery of ACL on functional outcomes.

Methods: 30 subjects following 5 months of ACL reconstruction were randomly assigned to either group that performed (study group) or did not performed (control group) additional core stabilization exercises in conjugation with standard rehabilitation protocol. Outcome measures were: activity level using Tegnar activity level scale and functional performance using triple hop test. Outcome measures were compared at day 1 and day 42 of the treatment.

Result: Significant improvement was seen in the study group for Tegnar score with mean difference changing from 4.5 to 1.5 from day 1 to day 42 of treatment $(p=0.039)$ while the control group showed improvement in mean difference changing from 3.8 to $1.4(p=.045)$ from day 1 to day 42 of treatment. Highly significant improvement was seen in the study group for triple hop test with mean difference changing from 25 to $6.7(\mathrm{p}<.001)$ compared to the control group with mean difference changing from 15.2 to $9.7(\mathrm{p}=.005)$ from day 1 to day 42 of treatment.

Conclusions: Both the groups showed improvement for activity level and functional performance but highly significant improvement was seen in the study group for functional performance. Core stabilization exercises in conjugation with the standard ACL rehabilitation protocol results better improvement in the triple hop test.

Keywords: ACL rehabilitation, Core-stabilization, Activity level, Functional performance.

Received $26^{\text {th }}$ September 2015, revised $19^{\text {th }}$ September 2015, accepted $12^{\text {th }}$ November 2015

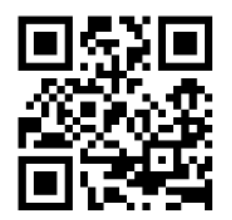

DOI: 10.15621/ijphy/2015/v2i6/80746

www.ijphy.org

\section{CORRESPONDING AUTHOR}

${ }^{2}$ Professor

Government Medical College and Hospital,

Chandigarh, Sec-32, Haryana 134107, India.

${ }^{3}$ Associate professor,

Mother Teresa Saket College of Physiotherapy

Chandimandir - Panchkula, Haryana 134107,

India.

\author{
${ }^{* 1}$ Dilpreet Kaur \\ MPT (Orthopedics) \\ Mother Teresa Saket College of \\ physiotherapy, \\ Chandimandir - Panchkula, \\ Haryana 134107, India.
}




\section{INTRODUCTION}

Return to play following ACL reconstruction is of significant concern amongst athletes following injury. ${ }^{1}$ A return to pre-injury level of sport represents most strong assessment of activity level outcome after ACL reconstruction. ${ }^{2}$ Athletes typically receive clearance to return to sport after ACL reconstruction surgery around 6 to 12 months post operatively and most are expected to return to sport within 12 months after surgery. ${ }^{3}$ It has been proved that $67 \%$ of athletes after ACL reconstruction surgery had returned to some form of sports activity participation and 33\% of athletes had attempted to play competitive sport at their pre-injury level at a mean of 13 months postoperatively. ${ }^{2}$

Core stability programs are being increasingly used for sports conditioning. Greater core stability benefits sports performance by providing greater force production in upper and lower extremity. Core exercises increases sensitivity of muscle spindles resulting in higher state of readiness to respond to forces applied to joint resulting in enhanced performance in sports. ${ }^{4,5}$ Rehabilitation protocol for athletes following ACL reconstruction includes routine exercises including range of motion and strengthening exercises with lesser stress placed on core stability exercises. ${ }^{6}$ The present study was conducted to study the effect of core stabilization exercises after reconstruction surgery of ACL on functional outcomes.

\section{MATERIALS AND METHODS}

The study was approved by Ethics cum Research committee of Mother Teresa Saket College of Physiotherapy, Panchkula, Haryana, India. A randomized controlled trial was conducted on 30 elite sports persons of level 1 sport for 6 week duration. Both males and females with age group of 15-35 year following 5 months of ACL reconstruction surgery having full knee range of motion and stable graft on KT1000 arthrometer were included in the study. Subjects with upper motor neuron/ lower motor neuron lesion, prolapsed intervertebral disc, knee osteoarthritis, any pathology of lower extremity, previous knee surgery, history of heart/ lung disease or patellofemoral joint irritation were excluded from study. Subjects were randomly divided into 2 groups with 15 subjects each by convenient random sampling method. The subjects were divided into group A (Control group) and group B (Study group). On the first day of treatment, all the subjects were asked to fill Tegnar activity level scale. Assessment for functional performance was done using triple hop test. Final assessment was done on day 42 of treatment.

Group A (Control group): Subjects in this group received conventional rehabilitation protocol. Exercises in this group included active knee range of motion exercises, quadriceps isometrics, hamstring isometrics, straight leg raising exercises, wall slides $\left(0-90^{\circ}\right)$, single leg squat and mini squat $\left(0-30^{0}\right)$ with bars. Each exercise was done with 10 repetitions per set and 3 sets per session for 5 times a week for 6 weeks duration. ${ }^{6}$

Group B (Study group): Subjects in this group received core stabilization exercises in conjugation with standard ACL rehabilitation protocol. Core stabilization exercises were divided into 3 stages with each stage lasting for 2 weeks. Core stabilization exercises consisted of static and dynamic exercises. Table 1 shows performed progressive core stabilization exercises. ${ }^{7}$

Each exercise was done with 10 repetitions per set and 3 sets per session. Dynamic exercises were done with 8 sec hold and 5 sec rest period. Static exercises consisted of $10 \mathrm{sec}$ hold and $5 \mathrm{sec}$ rest period. Abdominal drawing in maneuver was performed in conjunction with each dynamic exercise.

Table 1: Core stabilization exercises for Group B

STAGE 1 1. Abdominal tuck in in crook lying position (2 WEEKS)

STAGE 2 (2 WEEKS)

Abdominal tuck in in sitting position

STAGE 3 (2 WEEKS)
Abdominal tuck in in standing position

\section{Dynamic Exercises}

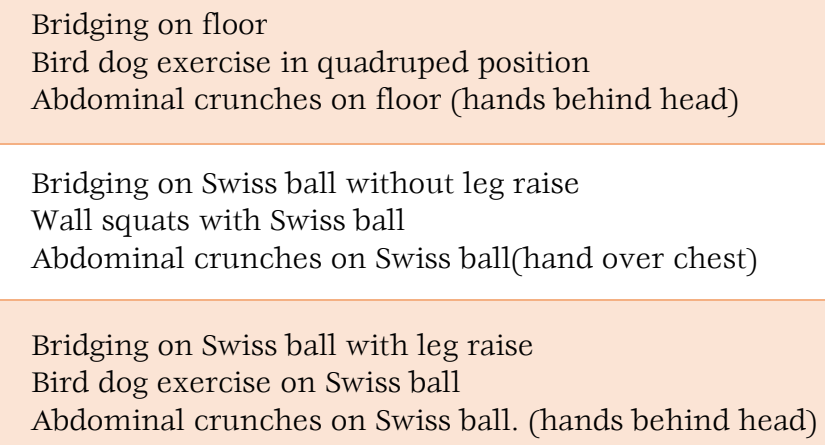




\section{Outcome Measures}

Activity Level: Tegnar activity level scale was used to measure activity level. It is a graduated list of activities of daily living, recreation, and competitive sports. It is a numerical scale ranging from 0 to 10. An activity level of 10 corresponds to participation in competitive sports at national level. Activity level of 6 indicated participation in recreational sports while 0 level was assigned if person was on sick leave because of knee problem. Patientwas asked to select the level of participation that best describes their current level of activity and that before injury. ${ }^{8}$

\section{Functional Performance}

Triple Hop Test: Patient was made to stand on a marked line and was then asked to take three long hop/ jump on one leg while landing on the same leg. Distance covered was measured and the test was repeated for opposite leg. Patient was made to repeat this test 3 times on each leg alternating sides and the average of all three hops was taken for each leg. ${ }^{9}$

Analysis of data collection of triple hop test and Tegnar activity level scale of 30 subjects was done by suitable statistical tests by using SPSS software 17.0 version.

\section{RESULTS}

Both the groups were matched for age. There were $20 \%$ females in control group and $6.7 \%$ females in study group. Table 2 shows gender and mean age of both the groups.

Table 2: Mean age and percentage of males and females in Group A and Group B

\begin{tabular}{|c|c|c|c|c|}
\hline Group & N & $\begin{array}{c}\text { Mean } \\
\text { Age }\end{array}$ & $\begin{array}{c}\text { Female } \\
\text { \%Within } \\
\text { Group }\end{array}$ & $\begin{array}{c}\text { Male } \\
\text { \%Within } \\
\text { Group }\end{array}$ \\
\hline A & 15 & 24.33 & $20 \%$ & $80 \%$ \\
\hline B & 15 & 23.80 & $6.7 \%$ & $93.3 \%$ \\
\hline
\end{tabular}

Changes in Tegnar activity level score showed improvement in study group with mean difference improving from 4.5 to 1.5 as compared to control group with mean difference changing from 3.8 to 1.4 from day 1 to day 42 of treatment. Table 4 shows mean change in activity level for both the groups. Significant improvement was seen in study group for activity level at day 42 of treatment with mean change in activity level of $3(p=.036)$ compared to control group with mean change in activity level of $2.4(p=.045)$. Table 5 compares the changes in activity level for both the groups.
Table 3: Comparison of mean, standard deviation and p-value for activity level of Group A and Group B from day 1 to day 42 of treatment

\section{MEAN CHANGE IN ACTIVITY LEVEL}

\begin{tabular}{|c|c|c|c|c|c|}
\hline GROUP & N & Mean & $\begin{array}{c}\text { Std. } \\
\text { deviation }\end{array}$ & $\begin{array}{c}\text { Std. } \\
\text { error } \\
\text { mean }\end{array}$ & $\begin{array}{c}\text { P } \\
\text { value }\end{array}$ \\
\hline A & 15 & 2.4000 & .82808 & .21381 & .045 \\
\hline B & 15 & 3.0000 & .65465 & .16903 & .039 \\
\hline
\end{tabular}

Improvement in both the groups in triple hop test for mean difference between day 1 and day 42 of treatment was 5.49 and 18.36 in group A and group B respectively. Highly significant improvement was seen in study group $(p<.001)$ and a significant improvement was seen in control group $(p=.005)$ at day 42 of the treatment. Table 4 compares mean difference for both the groups.

Table 4: Comparison of mean, standard deviation and p-value for triple hop test of Group A and Group B from day 1 to day 42 of treatment

\begin{tabular}{|c|c|c|c|c|c|}
\multicolumn{5}{|c|}{ Mean Change in Distance for Triple Hop } \\
Test \\
GROUP & N & Mean & $\begin{array}{c}\text { Std. } \\
\text { deviation }\end{array}$ & $\begin{array}{c}\text { Std. } \\
\text { error } \\
\text { mean }\end{array}$ & $\begin{array}{c}\text { P } \\
\text { value }\end{array}$ \\
\hline A & 15 & 5.49 & 6.36480 & 1.643 & .005 \\
\hline B & 15 & 18.36 & 8.42681 & 2.175 & $<.001$ \\
\hline
\end{tabular}

\section{DISCUSSION}

Core stability is product of motor control and muscular capacity of lumbo-pelvic hip complex. Ben kibler et $\mathrm{al}^{10}$ studied the role of core stability in athletic function. It was found that core stability results in proximal stability for distal mobility by creating interactive moments that move and protect distal joints. They observed that core activation results in anticipatory postural adjustments which help the body to withstand balance when forces are created during kicking, throwing or running activities. Thus, core activation was thought to create proximal stability for distal mobility improving performance level of athletes. Their study concluded that rehabilitation programs should not only include restoring core but also include core as base for extremity function. In the current study, functional performance of athletes following ACL reconstruction surgery was improved when standard ACL rehabilitation protocol was applied in conjugation with core stabilization protocol.

Kulandaivelan et $\mathrm{al}^{11}$ found that progressive core stabilization exercises of 6 weeks duration increases strength and endurance of core muscles. 
Exercises progressed from training isolated muscles to integrated system of muscles in order to facilitate functional activity. They found that 6 weeks program induces hypertrophy of Transverse Abdominis and Multifidus. This results in 70\% of maximum voluntary contraction of core muscles promoting strength in abdominal muscles. Kelly et al ${ }^{12}$ found that swiss ball exercises successfully recruit wide range of core musculature including local and global stabilizers and global mobilizers for improving core stability. The present study thus utilizes 6 weeks of core stabilization protocol following ACL reconstruction for improving functional performance in conjugation with the standard ACL rehabilitation protocol.

Nicholas et $\mathrm{al}^{9}$ observed that outcome measures utilized following ACL reconstruction surgery currently includes functional performance test namely hop test, jump, sprint and agility test. They further observed that interclass correlation coefficient (ICC) for triple leg hop test was 0.90 making it highly reliable and valid test for measuring functional performance in ACL reconstructed knee. It was concluded that functional performance tests namely single leg hop test, triple hop test and stair hop test has the potential to yield valuable information to clinician regarding athlete's status following knee ligament injury. The present study utilizes triple hop test for measuring functional performance in athletes following ACL reconstruction surgery.

Activity participation is important for establishing outcome for ACL reconstructed subjects. Nick Caplan et $\mathrm{l}^{13}$ found that many activity scales such as Lysholm scale and Function Elements of Knee Society Rating Scale evaluates patients ability to perform typical activity of daily living without any indication of patient's prior involvement in more demanding recreational and competitive sports. They found that tegnar activity scale allows clinician to evaluate success of clinical intervention in terms of whether patient is able to return to its pre-injury activity level. Tegnar activity rating scale was designed to complement other functional scores for patients with ligament injuries. Brigg et $\mathrm{al}^{14}$ found that tegnar scale have accepted test-retest reliability and did not show floor or ceiling effects. The present study utilizes tegnar activity level scale for assessing activity level in patients who performed or did not performed additional core stabilization exercises following ACL reconstruction.

The limitation of the present study is small sample size. Furthermore, the duration of this study is short. Final follow up was at $6^{\text {th }}$ week due to logistic reason as the study was part of a dissertation. However, the advantage of the present study is that it gives a clue that adding core stabilization exercises in ACL reconstruction rehabilitation protocol can result in better functional performance. Future studies should be performed with larger sample size and long follow up to further strengthen our observations.

\section{CONCLUSION}

The present study concluded that the core stabilization exercises in conjugation with standard ACL rehabilitation protocol results better improvement in triple hop test as well as Tegnar activity level score. Performance of players with ACL reconstructed knee can thus be increased by adding core stabilization exercise in standard rehabilitation protocol.

\section{REFRENCES}

1. Kirk A. McCullough, Kevin D. Phelps and Kurt P. Spindler. Return to high school and college level football following ACL reconstruction: a MOON cohorot study. Am J sports medicine. 2012;40(11):2523-2529.

2. Clare L. Andern, Kate E. Webster, Nicholas F. Taylor and Jullian Feller. Return to pre-injury level of competitive sport after ACL reconstruction surgery. Am J sports medicine. 2011; 39(3):538-43.

3. Myklebust G, Bahr R. Return to play guideline after ACL surgery. Br J sports medicine.2005;39(3):127-131.

4. Jaffrey M. Willardson. Core stability training: application to sports conditioning programs. Journal of strength and conditioning research. 2007;21(5):979-985.

5. W. Benkibler, Joel Press. Role of core stability in athletic function. Journal of sports medicine.2006;36(3):189-198.

6. May Arna Risberg, Inger Holm, Grethe Mykelbust and Lars Engebretsen. Neuromuscular training versus strength training during first 6 months after ACL reconstruction: a randomized clinical trial. Phys Ther. 2007;87(6):737-750.

7. Cissik, John M. The Role of Core Training in Athletic Performance, Injury Prevention, and Injury Treatment. Strength \& Conditioning Journal. 2011;33(1):10-15

8. Karen K, Briggs, Minninder S Kochar. Reliability, validity and responsiveness of lysholm score and tegnar activity level scale for patients with knee injuries. Journal of bone and joint surgery. 2006; 88(4):698-705. 
9. R Tyler Hamilton, Nicholas, Sandra J Shultz, Randy J.S. triple hop distance as a valid predictor of lower limb strength and power. J Athl Training. 2008;43(2):144-151.

10. W. Ben kibler, Joel Press. Role of core stability in atheletic function. Journal of sports medicine. 2006;36(3):189-198.

11. Kulandaivelan S, Chaturvedi R. Efficacy of progressive core strengthening exercises on functional endurance test and hypertrophy of multifidus, transverse abdominis in healthy female subjects with low core endurance.
Journal of exercise science and physiotherapy. ,2014;10(2):114-121.

12. Kellie C. Huxel Bliven. Core stability training for injury prevention. Sports Health. 2013 Nov; 5(6): 514-522.

13. Tegner $Y$, Lysholm J. Rating systems in the evaluation of knee ligament injuries. Clin Orthop Relat Res. 1985;198:43-9.

14. Briggs, lysholm and tegnar. The reliability, validity and responsiveness of lysholm and tegnar activity scale for ACL injuries of knee: 25 years later. Arm J sports medicine. 2009;37(5):890-7.

\section{Appendix: Master chart}

\begin{tabular}{|c|c|c|c|c|c|c|c|c|c|c|c|c|c|c|}
\hline \multirow{3}{*}{$\begin{array}{c}\text { SUBJE } \\
\text { CT } \\
\text { CODE }\end{array}$} & \multirow{3}{*}{$\begin{array}{c}\mathrm{AG} \\
\mathrm{E}\end{array}$} & $\begin{array}{l}\text { GE } \\
\text { ND }\end{array}$ & \multicolumn{6}{|c|}{ TEGNAR ACTIVITY LEVEL SCORE } & \multicolumn{6}{|c|}{ TRIPLE HOP TEST } \\
\hline & & & \multicolumn{3}{|c|}{ DAY 1} & \multicolumn{3}{|c|}{ DAY 42} & \multicolumn{3}{|c|}{ DAY 1} & \multicolumn{3}{|c|}{ DAY 42} \\
\hline & & & $\begin{array}{l}\text { BEF } \\
\text { ORE }\end{array}$ & $\begin{array}{c}\text { AFT } \\
\text { ER }\end{array}$ & $\begin{array}{c}\text { DIFFER } \\
\text { ENCE }\end{array}$ & $\begin{array}{l}\text { BEF } \\
\text { ORE }\end{array}$ & $\begin{array}{l}\text { AFT } \\
\text { ER }\end{array}$ & $\begin{array}{c}\text { DIFFER } \\
\text { ENCE }\end{array}$ & $\begin{array}{l}\text { INVOL } \\
\text { VED }\end{array}$ & $\begin{array}{l}\text { UNINVO } \\
\text { LVED }\end{array}$ & $\begin{array}{c}\text { DIFFER } \\
\text { ENCE }\end{array}$ & $\begin{array}{l}\text { INVOL } \\
\text { VED }\end{array}$ & $\begin{array}{l}\text { UNINV } \\
\text { OLVED }\end{array}$ & $\begin{array}{c}\text { DIFFER } \\
\text { ENCE }\end{array}$ \\
\hline A1 & 30 & M & 6 & 4 & 2 & 6 & 5 & 1 & 42 & 69 & 27 & 78 & 98 & 20 \\
\hline B1 & 28 & $\mathrm{M}$ & 6 & 2 & 4 & 6 & 5 & 1 & 59 & 80 & 21 & 88 & 99 & 11 \\
\hline A2 & 19 & $\mathrm{M}$ & 7 & 4 & 3 & 7 & 6 & 1 & 34 & 62 & 28 & 55 & 70 & 15 \\
\hline B2 & 20 & $\mathrm{M}$ & 7 & 4 & 3 & 7 & 6 & 1 & 103 & 130 & 27 & 129.1 & 133 & 3.9 \\
\hline A3 & 21 & $\mathrm{M}$ & 6 & 2 & 4 & 6 & 5 & 1 & 40 & 56.1 & 16.1 & 54 & 68 & 14 \\
\hline B3 & 22 & $\mathrm{M}$ & 9 & 4 & 5 & 9 & 8 & 1 & 157 & 207 & 50 & 191.5 & 209.5 & 18 \\
\hline A4 & 32 & $\mathrm{M}$ & 7 & 4 & 3 & 7 & 6 & 1 & 94 & 102.5 & 8.5 & 105 & 112 & 7 \\
\hline B4 & 24 & $\mathrm{M}$ & 9 & 4 & 5 & 9 & 6 & 3 & 132 & 146 & 14 & 150 & 152 & 2 \\
\hline A5 & 35 & $\mathrm{M}$ & 7 & 3 & 4 & 7 & 6 & 1 & 64 & 84.5 & 20.5 & 70 & 89 & 19 \\
\hline B5 & 29 & $\mathrm{M}$ & 10 & 4 & 6 & 10 & 8 & 2 & 128 & 142 & 14 & 151 & 152 & 1 \\
\hline A6 & 24 & $\mathrm{M}$ & 7 & 4 & 3 & 7 & 6 & 1 & 48 & 60 & 12 & 62 & 72 & 10 \\
\hline B6 & 21 & $\mathrm{M}$ & 10 & 4 & 6 & 10 & 7 & 3 & 98 & 109 & 11 & 129.8 & 132 & 2.2 \\
\hline A7 & 25 & $\mathrm{M}$ & 8 & 4 & 4 & 8 & 5 & 3 & 101 & 115 & 14 & 111 & 118 & 7 \\
\hline B7 & 23 & $\mathrm{M}$ & 6 & 2 & 4 & 6 & 5 & 1 & 99.8 & 138 & 38.2 & 126 & 139 & 13 \\
\hline A8 & 21 & M & 6 & 4 & 2 & 6 & 5 & 1 & 126 & 138 & 12 & 141 & 150 & 9 \\
\hline B8 & 24 & $\mathrm{M}$ & 7 & 3 & 4 & 7 & 6 & 1 & 88 & 110 & 22 & 100.2 & 111.2 & 11 \\
\hline A9 & 28 & $\mathrm{M}$ & 6 & 2 & 4 & 6 & 5 & 1 & 97 & 112 & 15 & 120 & 128 & 8 \\
\hline B9 & 24 & M & 10 & 6 & 4 & 10 & 9 & 1 & 82 & 114 & 32 & 106.9 & 115.8 & 8.9 \\
\hline A10 & 26 & $\mathrm{M}$ & 6 & 2 & 4 & 6 & 5 & 1 & 61 & 85 & 24 & 90 & 89 & 1 \\
\hline B10 & 25 & M & 10 & 5 & 5 & 10 & 8 & 2 & 88 & 128 & 40 & 112 & 128 & 16 \\
\hline A11 & 16 & $\mathrm{~F}$ & 6 & 4 & 2 & 6 & 7 & 1 & 92 & 100 & 8 & 121 & 128 & 7 \\
\hline B11 & 22 & $\mathrm{M}$ & 9 & 5 & 4 & 9 & 8 & 1 & 123 & 151.9 & 28.9 & 149.5 & 153 & 3.5 \\
\hline A12 & $2 \mathrm{O}$ & $\mathrm{M}$ & 10 & 2 & 8 & 10 & 5 & 5 & 126 & 138 & 12 & 139 & 148 & 9 \\
\hline B12 & 21 & $\mathrm{M}$ & 9 & 4 & 5 & 9 & 7 & 2 & 132 & 146 & 14 & 151 & 152 & 1 \\
\hline A13 & 21 & $\mathrm{~F}$ & 6 & 4 & 2 & 6 & 7 & 1 & 82 & 92 & 10 & 91 & 100.2 & 9.2 \\
\hline B13 & 31 & $\mathrm{M}$ & 10 & 4 & 6 & 10 & 8 & 2 & 102.5 & 107.5 & 5 & 117 & 115 & 2 \\
\hline A14 & 32 & $\mathrm{~F}$ & 9 & 5 & 4 & 9 & 8 & 1 & 98 & 109 & 11 & 109.5 & 118.5 & 9 \\
\hline B14 & 26 & $\mathrm{M}$ & 9 & 6 & 3 & 9 & 8 & 1 & 108 & 142 & 34 & 148 & 150 & 2 \\
\hline A15 & 24 & $\mathrm{M}$ & 10 & 5 & 5 & 10 & 8 & 2 & 148 & 158 & 10 & 235 & 238.5 & 3.5 \\
\hline B15 & 17 & $\mathrm{~F}$ & 6 & 2 & 4 & 6 & 5 & 1 & 21 & 46 & 25 & 45.8 & 55 & 9.2 \\
\hline
\end{tabular}

\begin{tabular}{|c|c|c|c|c|c|}
\hline & $\begin{array}{c}\text { MEAN } \\
\text { AGE }\end{array}$ & $\begin{array}{c}\text { TEGNAR ACTIVITY LEVEL } \\
\text { MEAN DIFFERENCE DAY 1 }\end{array}$ & $\begin{array}{c}\text { TEGNAR ACTIVITY } \\
\text { LEVEL MEAN } \\
\text { DIFFERENCE DAY 42 }\end{array}$ & $\begin{array}{c}\text { TRIPLE HOP } \\
\text { TEST MEAN } \\
\text { DIFFERNCE } \\
\text { DAY 1 }\end{array}$ & $\begin{array}{c}\text { TRIPLE HOP } \\
\text { TEST MEAN } \\
\text { DIFFERENCE } \\
\text { DAY 42 }\end{array}$ \\
\hline $\begin{array}{c}\text { Grou } \\
\text { p A }\end{array}$ & 24.33 & 3.80 & 1.40 & 15.20 & 9.71 \\
\hline $\begin{array}{c}\text { Grou } \\
\text { p B }\end{array}$ & 23.80 & 4.53 & 1.53 & 25.07 & 6.71 \\
\hline
\end{tabular}


Citation

Dilpreet Kaur, Ravi Gupta, \& Shikha. (2015). CORE STABILIZATION EXERCISES AFTER ACL RECONSTRUCTION SURGERY PROVIDES BETTER OUTCOMES: A RANDOMIZED CONTROLLED TRIAL. International Journal of Physiotherapy, 2(6), 899-904. 